\title{
Studying the infection rate of seeds of various genotypes of sweet sorghum (Sorghum bicolor L.) by fungus and bacterial microflora
}

\author{
K.M. Iskakova ${ }^{1}$, B.B. Anapiyayev ${ }^{1 *}$, E.B. Beisenbek ${ }^{1}$, A.B. Akhmetova ${ }^{2}$, A.M. Sagimbayeva ${ }^{1}$, A.S. Omarova ${ }^{3}$ \\ ${ }^{1}$ Kazakh National Research Technical University named after K.I. Satpaev, Almaty, Kazakhstan \\ ${ }^{2}$ Kazakh National Agrarian University, Almaty, Kazakhstan \\ ${ }^{3}$ Institute of Agriculture, Almalybak, Almaty region, Kazakhstan
}

DOI 10.18699/ICG-PlantGen2019-25

(c) Autors, 2019

* e-mail: bak_anapiyayev@mail.ru

\begin{abstract}
It was revealed that the sowing material of sweet sorghum (Sorghum bicolor L.) was injured with fungus and bacterial microflora. Studying the seed material of sweet sorghum demonstrated that it was injured with microflora, belonging to the genera Fusarium, Alternaria, Penicillium, Aspergillus, Mucor and Helminthosporium causing seed moulding and rotting. The genotypes and seed material of sweet sorghum most injured with fungus and bacterial microflora were determined. The germination energy and seed viability of various genotypes of sweet sorghum were determined. The infection rate of seed material considerably influenced the germination energy and seed viability of sweet sorghum. The injury of seeds by fungus and bacterial microflora is an important indicator defining the field viability of seeds and affecting the productivity of sweet sorghum.
\end{abstract}

Key words: swet sorghum; Sorghum bicolor L.; fungus and bacterial microflora; Fusarium; Alternaria; Penicillium; Aspergillus; Mucor; Helminthosporium.

\section{Introduction}

Sorghum is a valuable thermophilic spring-planted cereal culture, which resembles in appearance corn and is not inferior to it in terms of nutritious properties. Four main sorghum species are distinguished: grainy, sweet, grassy and broomy. The homeland to sorghum is Northeast Africa and Equatorial Africa, particularly Ethiopia and Sudan; it has also been cultivated in China and India since long time ago. Therefore sweet sorghum (Sorghum saccharatum Pers.) is the most drought-resistant culture. Sweet sorghum is characterized by the fact that, unlike grainy and broomy sorghum, the juice of its stem contains more than $10-20 \%$ of soluble sugars. In the nature, there is no other plant which could synthesize sucrose so quickly as sweet sorghum does. As it can be cultivated in southern droughty areas, where growing sugar beet is unprofitable or impossible, interest to sweet sorghum is very high. Sweet sorghum is a perspective crop for multi-purpose use. Sweet sorghum is used in bread baking and in production of forages and cardboard. Nowadays the biotechnological aspects of cultivation of sweet sorghum cells in vitro for the extension of genetic diversity are being studied (Baskaran et al., 2005; Dora et al., 2014; Teingham, Borde, 2017; Omer et al., 2018). Research in the genetic engineering of sorghum is intensive (Guel et al., 2009).

Factors affecting the quality of cellular juice and the power value of sweet sorghum depending on terms of sowing, depth of seed embedding and the use of nitrogen fertilizers were studied (Maw et al., 2016). Special attention was given to studying the cultivars and hybrids of sweet sorghum with a high content of sugar for bioethanol production. Molecular mechanisms of the resistance of sweet sorghum to biotic and abiotic stressful environmental factors were studied (Anami et al., 2015). At the same time, for cultivation of sweet sorghum, it is necessary to study factors that ffect the viability of seeds and productivity. One of the limiting factors affecting the viability of seeds in sweet sorghum is the injury of seed material with fungus and bacterial microflora. In this regard, the level of injury of seeds of sweet sorghum (Sorghum bicolor L.) cultivated in the conditions of the southeastern part of Kazakhstan were studied by us.

\section{Materials and methods}

The sweet sorghum genotypes SAB-1, SAB-2, SAB-3, SAB-4, SAB- 5, SAB-6, SAB-8, SAB-9, B-10, SAB-11 and SAB-12 were used as material for our research. During the analysis of seeds of different genotypes of sweet sorghum, their sowing qualities, such as germination energy on the $4^{\text {th }}$ day and the laboratory germination viability on the $8^{\text {th }}$ day, were estimated against state standard specifications. Fifty seeds of each genotype in 3-fold repetition were taken to determine their sowing qualities in the conditions of the moisture chambers. The number of infected seeds and sprouts was also noticed. Microflora was placed on the nutrient medium made of potato agar (PA). During this analysis, the lack of microflora was designated as (-), weak growth, as (+), the average growth, as $(++)$, and intensive growth, as $(+++)$. The identification of fungus and bacterial microflora was carried out by morphological and cultural features of colonies of fungi and bacteria and their pure cultures. Morphological features of fungi were investigated by microscopy according to their spore forming. Bacterial microflora was selected into a pure culture and checked for pathogenicity using test objects such as a room geranium and tubers of potatoes. It was noted that pathogenic species of bacteria on geranium leaves caused a reaction of supersensitivity in the form of necrosis; on tubers of potatoes, it caused tissue maceration (rotting). Statistical analysis of the results obtained was carried out using the standard technique.

\section{Results and discussion}

Before sowing the various genotypes of sorghum in field conditions, the seed viability of sweet sorghum in vitro was studied. The seed viability of sorghum was affected by such 
Table 1

Sowing qualities of seeds of sweet sorghum, laboratory experiment, the moisture chamber

\begin{tabular}{lllll}
\hline \multirow{2}{*}{$\begin{array}{l}\text { Crop, } \\
\text { cultivar } \\
\text { (genotype) }\end{array}$} & $\begin{array}{l}\text { Germination } \\
\text { energy, } \%\end{array}$ & $\begin{array}{l}\text { Laboratory } \\
\text { germination } \\
\text { energy, } \%\end{array}$ & $\begin{array}{l}\text { Number of } \\
\text { infected seeds } \\
\text { and sprouts, }\end{array}$ \\
\cline { 3 - 4 } & & \multicolumn{2}{c}{ days of observation } & \\
\cline { 3 - 4 } & & $4^{\text {th }}$ & $8^{\text {th }}$ \\
\hline 1 & SAB-1 & 78.0 & 78.0 & 100 \\
2 & SAB-2 & 76.0 & 79.3 & 78.6 \\
3 & SAB-3 & 2.0 & 2.6 & 93.3 \\
4 & SAB-4 & 88.6 & 90.6 & 14.0 \\
5 & SAB-5 & 45.3 & 53.3 & 14.0 \\
6 & SAB-6 & 45.0 & 43.5 & 56.4 \\
7 & SAB-7 & 36.6 & 40.6 & 73.3 \\
8 & SAB-8 & 81.3 & 88.0 & 3.3 \\
9 & SAB-9 & 100 & 100 & 30.6 \\
10 & SAB-10 & 96.6 & 98.0 & 25.3 \\
11 & SAB-11 & 32.0 & 32.0 & 100 \\
12 & SAB-12 & 98.0 & 98.6 & 88.0 \\
\hline
\end{tabular}

factors as the initial cultivar genotype, periods of seed storage and the recontamination of sorghum grains by various microorganisms.

It was revealed that on the $4^{\text {th }}$ day amicable and full-fledged sprouts were noted in genotypes SAB-1, 2, 4, 8, 9, 10 and 11 (78; 76; 88.6; 81.3; 100; 96.6 and $98 \%$, respectively). The germination energy of genotypes SAB-5, 6, 7 and 11 was $45.3,45.0,36.6$, and $32.0 \%$, respectively; genotype SAB-3 possessed weak viability, only $2.0 \%$ (Table 1 ).

According to data from Table 1 , on the $4^{\text {th }}$ day amicable and full-fledged shoots were noted in genotypes SAB-1, 2, 4, 8, 9, 10 and 12 . They were $78 ; 76 ; 88.6 ; 81.3 ; 100 ; 96.6$ and $98 \%$, respectively. The germination energy in genotypes SAB-5, 6 , 7 and 11 was $45.3,45.0,36.6$ and $32.0 \%$, respectively, and genotype SAB-3 possessed weak viability, about $2.0 \%$.

Germination on the $8^{\text {th }}$ day in genotypes SAB-8, 9, 10 and 12 corresponded to the standards of the original and elite cultivars. The viability of genotypes SAB-1 and SAB-2 corresponded to the standards of reproductive cultivars for production: 78 and $79.3 \%$, respectively. Other seeds showed a very low germination: $32.0-53.3 \%$. The viability of genotype SAB-3 was only $2.6 \%$.

Strong damage to seeds and sprouts caused by diseases was also noted (Figure 1). The greatest number of infected seeds and sprouts in genotypes SAB-1, 2, 3, 7, 11 and 12 reached $100,78.6,93.3,73.3,100$ and $88 \%$, respectively. In other variants, infection varied from 3.3 to $56.4 \%$.

Studying the level of injury of sweet sorghum seeds by fungus and bacterial microflora was carried out on potato agar. The results of these studies are presented in Table 2. According to data from the Table 2, in all tests of seeds after surface sterilization on the nutrient medium fungus and bacterial infections were revealed (Figure 2). The highest rates of
Table 2

Phytoexamination of sweet sorghum seeds,

laboratory experiment, nutrient medium, 2018

\begin{tabular}{|c|c|c|c|c|c|c|}
\hline \multirow[t]{4}{*}{ № } & \multirow{4}{*}{$\begin{array}{l}\text { Crops, } \\
\text { cultivar }\end{array}$} & \multirow{4}{*}{$\begin{array}{l}\text { Number of } \\
\text { the infected } \\
\text { seeds and } \\
\text { sprouts, \% }\end{array}$} & \multicolumn{4}{|c|}{ Infection by microflora } \\
\hline & & & \multicolumn{2}{|c|}{ fungus } & \multicolumn{2}{|c|}{ bacterial } \\
\hline & & & \multicolumn{4}{|c|}{ days of observation } \\
\hline & & & $3^{\text {rd }}$ & $5^{\text {th }}$ & $3^{\text {rd }}$ & $5^{\text {th }}$ \\
\hline 1 & SAB-1 & 100.0 & +++ & +++ & +++ & +++ \\
\hline 2 & SAB-2 & 100.0 & ++ & ++ & +++ & +++ \\
\hline 3 & SAB-3 & 92.8 & + & ++ & ++ & +++ \\
\hline 4 & SAB-4 & 100.0 & - & ++ & ++ & ++ \\
\hline 5 & SAB-5 & 100.0 & + & + & ++ & ++ \\
\hline 6 & SAB-6 & 100.0 & + & + & ++ & + \\
\hline 7 & SAB-7 & 100.0 & + & + & ++ & ++ \\
\hline 8 & SAB-8 & 100.0 & + & ++ & + & +++ \\
\hline 9 & SAB-9 & 100.0 & - & ++ & ++ & +++ \\
\hline 10 & SAB-10 & 92.8 & + & ++ & ++ & +++ \\
\hline 11 & SAB-11 & 100.0 & +++ & +++ & +++ & +++ \\
\hline 12 & SAB-12 & 98.6 & + & + & ++ & + \\
\hline
\end{tabular}

injury by fungus and bacterial microflora were found in two sorghum genotypes, SAB-1 and SAB-11. Two other sweet sorghum genotypes, SAB-6 and SAB-12, demonstrated weak infection by fungus and bacterial microflora.

Based on the morphological features of their colonies and according to a microscopic analysis of their spore formation, the fungi revealed were in the species Fusarium, Alternaria, Penicillium, Aspergillus, Mucor and Helminthosporium causing seed moulding and rotting and also causing the rot of the root system.

Results of identification of bacteria on the basis of morphological features of their colonies on the nutrient medium and checking their pathogenic features on the test objects, a room geranium and tubers of potatoes, demonstrated their identity with phytopathogenic bacteria in the genera Erwinia and Pseudomonas causing different types of bacterioses.

On the basis of the phytoexamination carried out on sweet sorghum seeds, it was established that not every sample of seed material of the genotypes of this crop conformed to the State standard requirements in terms of sowing qualities. Additionally, their affection by a wide range of saprotrophic and pathogenic microflora was revealed.

\section{Conclusions}

As a result of the laboratory and field studies carried out, it was established that not all studied samples of seed material of sweet sorghum (Sorghum bicolor L.) conformed to the State standard requirements in terms of sowing qualities. Additionally, their affection by a wide range of saprotrophic and pathogenic microflora was revealed.

During the study of seed germination of sorghum of original and elite cultivars, it was revealed that not all the genotypes of sugar sorghum demonstrated a high level of viability. It was 


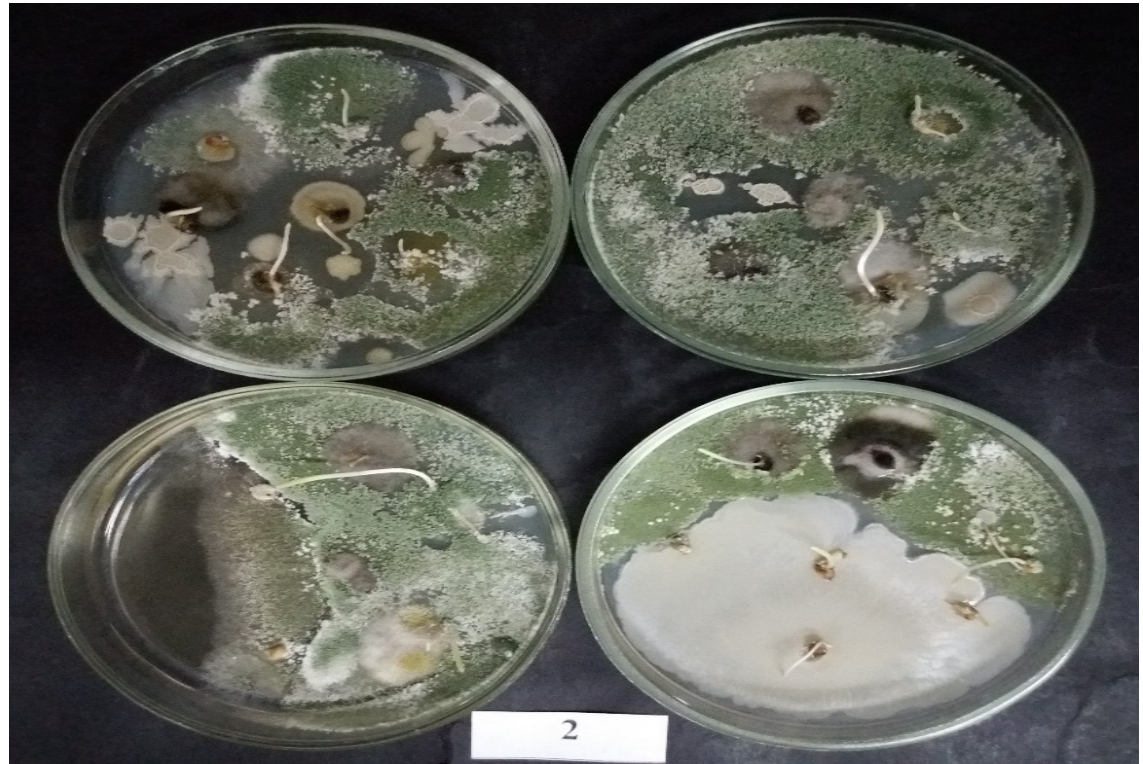

Figure 1. The seeds of sweet sorghum injured with fungus and bacterial microflora, laboratory experiment, 2018; genotypes SAB-2 and SAB-3. revealed that the laboratory viability of tgenotypes SAB-8, 9, 10 and 12 were consistent with the standards of the original and elite cultivars. The respective viabilities of genotype SAB-1 was $78 \%$ and SAB- 2 was $79.3 \%$ consistent with the standards of reproductive cultivars for production. Other seed material demonstrated a very low laboratory viability, 32.0-53.3\%. The viability of genotype SAB-3 was only $2.6 \%$.

Strong injury of seeds and sprouts by diseases was also noted. The greatest number of infected seeds and sprouts was revealed in genotypes SAB-1, 2, 3, 7, 11 and 12 (100, 78.6, $93.3,73.3,100$ and $88 \%$, respectively). In other experimental variants, the infection level varied from 3.3 to $56.4 \%$.

Studies the seeds of sweet sorghum for fungal and bacterial infection rates were carried out on potato agar. At the same time, in all test samples of seeds after surface sterilization on the nutrient medium fungus and bacterial infections were revealed. Based on the morphological features of their colonies and according to a microscopic analysis of their spore formation, the fungi revealed were in the species Fusarium, Alternaria, Penicillium, Aspergillus, Mucor and Helminthosporium, which are able to cause seed molding and rotting and also root rots.

In the result of the study conducted, the genotypes and seed material of sweet sorghum most infected with fungus and bacterial microflora were determined. The energy of germination and viability of seeds of the various genotypes of sweet sorghum were also determined. The germination energy and seed viability of sweet sorghum were considerably affected by the infection rate of seed material. Studying the infection rate of seeds by fungus and bacterial microflora is an important indicator of the field viability of seeds and productivity of sweet sorghum (Sorghum bicolor L.).

\section{References}

Anami S.E., Zhang L.M., Xia Y. et al. Sweet sorghum ideotypes: genetic improvement of stress tolerance. Food Energy Security. 2015; 4(1):3-24

Baskaran P., Rajevari B.R., Jayabalan N. A simple approach to improve plant regeneration from callus culture of Sorghum bicolor for crop improvement. J. Agriculture Technol. 2005;1(1):179-192.

Dora S.V., Sharma P., Sandra M.N. Efficient callus induction protocol for Sorghum bicolor. Asian J. Plant Sci. Res. 2014;4(3):14-21.

Gurel S., Gurel E., Kaur R. et al. Efficient, reproducible Agrobacterium-mediated transformation of sorghum using heat treatment of immature embryos. Plant Cell Rep. 2009;28:429-444.

Maw M.J.W., Houx III J.H., Fritschi F.B. Sweet sorghum ethanol yield component response to nitrogen fertilization. Industrial Crops Products. 2016;84:43-49.

Omer A.R., Asami P., Birungi J. Callus induction and plant regeneration from immature embryos of sweet sorghum (Sorghum bicolor Moench). Biotechnology. 2018;17(1):12-18.

Teingtham K., La Borde N.D. Is double haploid production in sorghum impossible? Int. J. Appl. Sci. Technol. 2017;10:4:247-256.

Acknowledgments. This study was supported in the framework of the Target Financing Program of the Science Committee of the Ministry of Education and Science of the Republic of Kazakhstan by project no. BR05236302.

Conflict of interest. The authors declare no conflict of interest. 